\title{
Design and Synthesis of Luminescent Bis(isocyanoborato) Rhenate(I) Complexes as a Selective Sensor for Cyanide Anion
}

Yelan Xiao, Wing-Kin Chu, Chi-On Ng, Shun-Cheung Cheng, Man-Kit Tse, Shek-Man Yiu, Chi-Chiu $\mathrm{Ko}^{*}$

Department of Chemistry, City University of Hong Kong, Tat Chee Avenue, Kowloon, Hong Kong, China.

\section{Supporting Information}


Physical Measurements and Instrumentation. ${ }^{1} \mathrm{H},{ }^{19} \mathrm{~F}$ and ${ }^{13} \mathrm{C}$ spectra were recorded on a Bruker AV400 (400 MHz) and Bruker AV600 (600 MHz) FT-NMR spectrometer. Chemical shifts $(\delta, \mathrm{ppm})$ were reported relative to tetramethylsilane $\left(\mathrm{Me}_{4} \mathrm{Si}\right)$. All positive ESI mass spectra were recorded on PE-SCIEX API 150 EX single quadrupole mass spectrometer. Mass spectra of neutral target complexes were obtained in acetonitrile solution with a small quantity of potassium iodide to improve the detection sensitivity. Elemental analyses were performed on an Elementar Vario MICRO Cube elemental analyzer. IR spectra of the solid samples as KBr disks were recorded in the range of 400-4000 $\mathrm{cm}^{-1}$ using an AVATAR 360 FTIR spectrometer.

All of the electronic absorption spectra were recorded on a Hewlett-Packard 8453 or HewlettPackard 8452A diode array spectrophotometer. Steady state emission and excitation spectra at room temperature were recorded on a Horiba Jobin Yvon Fluorolog-3-TCSPC spectrofluorometer. The solutions were rigorously degassed on a high vacuum line in a two-component cell with not less than four successive freeze-pump-thaw cycles. Measurements of the EtOH/MeOH (4:1 v/v) glass samples at $77 \mathrm{~K}$ were carried out with the dilute $\mathrm{EtOH} / \mathrm{MeOH}$ sample solution contained in a quartz tube inside a liquid-nitrogen-filled quartz optical Dewar flask. The solutions were rigorously degassed on a high vacuum line in a two-component cell with not less than four successive freeze-pump-thaw cycles. The luminescence quantum yields were determined using the optical-dilution method as described by Demas and Crosby ${ }^{1}$ with an aerated aqueous solution of $\left[\mathrm{Ru}(\mathrm{bpy}){ }_{3} \mathrm{Cl}_{2}\right]\left(\phi_{\mathrm{em}}=0.040\right)$ with excitation at $436 \mathrm{~nm}$ as the reference. ${ }^{2}$ Luminescence lifetimes were measured using time-correlated single photon counting (TCSPC) technique on the TCSPC spectrofluorometer in a Fast MCS mode with a NanoLED-375LH excitation source, which has its excitation peak wavelength at $375 \mathrm{~nm}$ and pulse width shorter than $750 \mathrm{ps}$. The photon counting data were analyzed by Horiba Jobin Yvon Decay Analysis Software. The electronic absorption spectral titration experiment was performed by a Hewlett-Packard 8452A diode array spectrophotometer while the emission spectral titration was performed on a Horiba Jobin Yvon FluoroMax-4 spectrofluorometer. In order to maintain a constant ionic strength, the supporting electrolyte $(0.1 \mathrm{KCl})$ in $\mathrm{MeCN} / \mathrm{H}_{2} \mathrm{O}(\mathrm{v} / \mathrm{v} 2: 1)$ was used in the electronic absorption and emission spectral anion titration studies.

Cyclic voltammetric measurements were performed by using a $\mathrm{CH}$ Instruments, Inc. Model CHI 620 Electrochemical Analyzer. Electrochemical measurements were performed in acetonitrile solutions with $0.1 \mathrm{M} \mathrm{nBu}_{4} \mathrm{NPF}_{6}$ as the supporting electrolyte at room temperature. The refer- 
ence electrode was an $\mathrm{Ag} / \mathrm{AgNO}_{3}$ (0.01M in acetonitrile) electrode, and the working electrode was a glassy carbon electrode ( $\mathrm{CH}$ Instruments, Inc.) with a platinum wire as the counter electrode. The working electrode surface was polished with a $1 \mu \mathrm{m} \alpha$-alumina slurry (Linde) and then a $0.3 \mu \mathrm{m} \alpha$-alumina slurry (Linde) on a microcloth (Buehler Co.). The ferrocenium/ferrocene couple $\left(\mathrm{FeCp}^{2+/ 0}\right)$ was used as the internal reference. All solutions for electrochemical studies were deaerated with pre-purified argon gas prior to measurements.

X-ray Crystal Structure Determination. The crystal structure of the complex anion of 1a was determined by an Oxford Diffraction Gemini S Ultra X-ray single crystal diffractometer using graphite monochromatized $\mathrm{Cu}_{K a}(\lambda=1.54178 \AA)$ radiation. The structure was solved by direct methods employing the SHELXL-97 program on PC. ${ }^{3} \mathrm{Re}$ and many non-H atoms were located according to the direct methods. The positions of other non-hydrogen atoms were found after successful refinement by full-matrix least-squares using the SHELXL-97 program on PC. In the final stage of least-squares refinement, all non-hydrogen atoms were refined anisotropically. $\mathrm{H}$ atoms were generated by the program SHELXL-97. The positions of hydrogen atoms were calculated based on the riding mode with thermal parameters equal to 1.2 times that of the associated $\mathrm{C}$ atoms, and participated in the calculation of final $R$-indices. A conventional index $R_{1}$ based on observed $F$ values larger than $4 s\left(F_{0}\right)$ is given (corresponding to intensity $\geq 2 s(I)$ ). $w R^{2}=$ $\left\{\Sigma\left[w\left(F_{\mathrm{o}}^{2}-F_{\mathrm{c}}^{2}\right)^{2}\right] / \Sigma\left[w\left(F_{\mathrm{o}}^{2}\right)^{2}\right]\right\}^{1 / 2}, R_{1}=\Sigma|| F_{\mathrm{o}}|-| F_{\mathrm{c}}|| \Sigma\left|F_{\mathrm{o}}\right|$. The Goodness of Fit is based on $F_{2}$ : $\mathrm{GooF}=S=\left\{\Sigma\left[w\left(F_{\mathrm{o}}^{2}-F_{\mathrm{c}}^{2}\right)^{2}\right] /(n-p)\right\}^{1 / 2}$, where $n$ is the number of reflections and $p$ is the total number of parameters refined. The weighting scheme is: $w=1 /\left[s^{2}\left(F_{0}^{2}\right)+(a P)^{2}+b P\right]$, where $P$ is $\left[2 F_{\mathrm{c}}{ }^{2}+\operatorname{Max}\left(F_{\mathrm{o}}^{2}, 0\right)\right] / 3$. 
Table S1. Selected bond distances $(\AA)$ and angles $\left({ }^{\circ}\right)$ with estimated standard deviations (e.s.d.s) in parentheses for $\mathbf{1 a}$ with ${ }^{\mathrm{n}} \mathrm{Bu} 4 \mathrm{~N}^{+}$counter cation.

\begin{tabular}{llll}
\hline $\operatorname{Re}(1)-\mathrm{C}(1)$ & $1.903(3)$ & $\mathrm{Re}(1)-\mathrm{C}(2)$ & $1.905(3)$ \\
$\operatorname{Re}(1)-\mathrm{C}(3)$ & $2.062(3)$ & $\operatorname{Re}(1)-\mathrm{C}(4)$ & $2.061(2)$ \\
$\operatorname{Re}(1)-\mathrm{N}(3)$ & $2.185(2)$ & $\operatorname{Re}(1)-\mathrm{N}(4)$ & $2.189(2)$ \\
$\mathrm{C}(1)-\mathrm{O}(1)$ & $1.167(3)$ & $\mathrm{C}(2)-\mathrm{O}(2)$ & $1.152(4)$ \\
$\mathrm{C}(3)-\mathrm{N}(1)$ & $1.153(3)$ & $\mathrm{C}(4)-\mathrm{N}(2)$ & $1.153(3)$ \\
$\mathrm{N}(1)-\mathrm{B}(1)$ & $1.540(3)$ & $\mathrm{N}(2)-\mathrm{B}(2)$ & $1.552(3)$ \\
& & & \\
$\mathrm{N}(3)-\operatorname{Re}(1)-\mathrm{N}(4)$ & $75.50(9)$ & $\mathrm{C}(3)-\mathrm{N}(1)-\mathrm{B}(1)$ & $175.5(3)$ \\
$\operatorname{Re}(1)-\mathrm{C}(3)-\mathrm{N}(1)$ & $171.1(2)$ & $\mathrm{C}(4)-\mathrm{N}(2)-\mathrm{B}(2)$ & $168.7(2)$ \\
$\operatorname{Re}(1)-\mathrm{C}(4)-\mathrm{N}(2)$ & $169.4(2)$ & & \\
\hline
\end{tabular}


Table S2. Crystal and structure determination data for $\mathbf{1 a}$ with ${ }^{\mathrm{n}} \mathrm{Bu} 4 \mathrm{~N}^{+}$.

\begin{tabular}{|c|c|}
\hline Empirical formula & $\mathrm{C}_{52} \mathrm{H}_{8} \mathrm{~B}_{2} \mathrm{~F}_{30} \mathrm{~N}_{4} \mathrm{O}_{2} \mathrm{Re} \cdot \mathrm{C}_{16} \mathrm{H}_{36} \mathrm{~N}$ \\
\hline Formula weight & 1740.90 \\
\hline $\mathrm{T} / \mathrm{K}$ & $133(2)$ \\
\hline$a / \AA$ & $14.0827(2)$ \\
\hline$b / \AA$ & $27.1716(5)$ \\
\hline$c / \AA$ & $28.9494(6)$ \\
\hline$\alpha /^{\circ}$ & $68.658(2)$ \\
\hline$\beta /^{\circ}$ & $83.034(2)$ \\
\hline$\gamma / 0$ & $84.2420(10)$ \\
\hline Volume / $\AA^{3}$ & $10222.7(3)$ \\
\hline Crystal system & Triclinic \\
\hline Space group & $\mathrm{P} \overline{1}$ \\
\hline $\mathrm{Z}$ & 6 \\
\hline $\mathrm{F}(000)$ & 5148 \\
\hline Density / $\mathrm{mg} \mathrm{m}^{-3}$ & 1.697 \\
\hline Crystal size / mm & $0.45 \times 0.21 \times 0.02$ \\
\hline Wavelength / $\AA$ & 1.54178 \\
\hline Absorption coefficient $/ \mathrm{mm}^{-1}$ & 4.686 \\
\hline Collection range & $\begin{array}{l}3.1268^{\circ} \leq \theta \leq 71.6501^{\circ} \\
(h:-11 \text { to } 16 ; k:-33 \text { to } 33 ; l:-34 \text { to } 35)\end{array}$ \\
\hline Completeness to theta & $97.4 \%$ \\
\hline No. of data collected & 82170 \\
\hline No. of unique data & 39027 \\
\hline No. of data used in refinement, $m$ & 33806 \\
\hline No. of parameters refined, $p$ & 3127 \\
\hline$R^{a}$ & 0.0302 \\
\hline$w R^{a}$ & 0.0771 \\
\hline Goodness-of-fit, $S$ & 1.018 \\
\hline Maximum shift, $(\Delta / \sigma)_{\max }$ & 0.001 \\
\hline Residual extrema in final difference map / $\mathrm{e} \AA^{-3}$ & $+1.427,-0.869$ \\
\hline
\end{tabular}




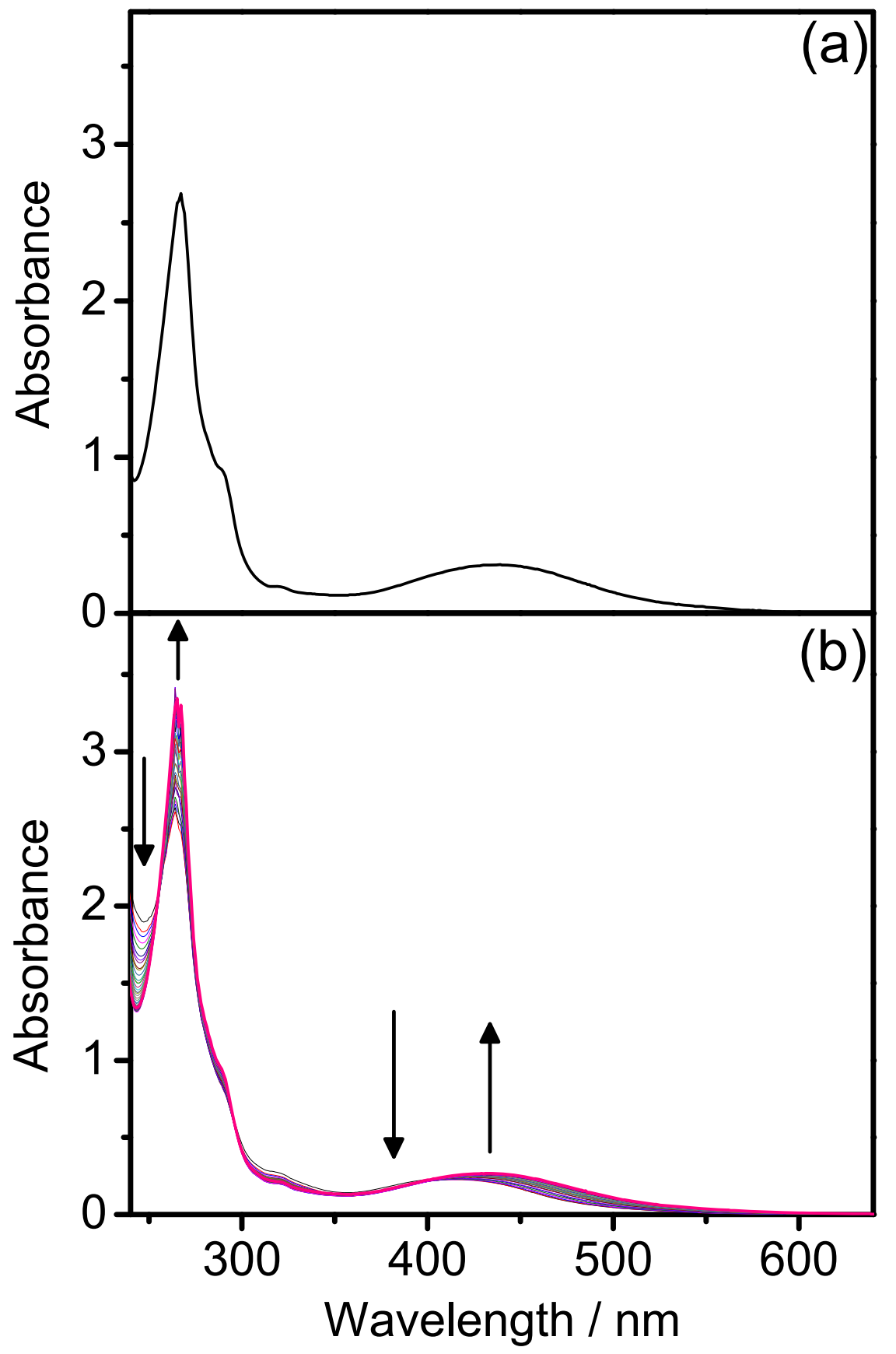

Figure S1. (a) UV-vis absorption spectrum of $\mathbf{P 1}$ in $0.1 \mathrm{M} \mathrm{KCl} \mathrm{MeCN} / \mathrm{H}_{2} \mathrm{O}(2: 1$, v/v) solution and (b) UV-vis absorption spectral changes of $\mathbf{1 b}$ in $0.1 \mathrm{M} \mathrm{KCl} \mathrm{MeCN} / \mathrm{H}_{2} \mathrm{O}(2: 1$, $\mathrm{v} / \mathrm{v}$ ) solution upon addition of different amounts of KCN. 

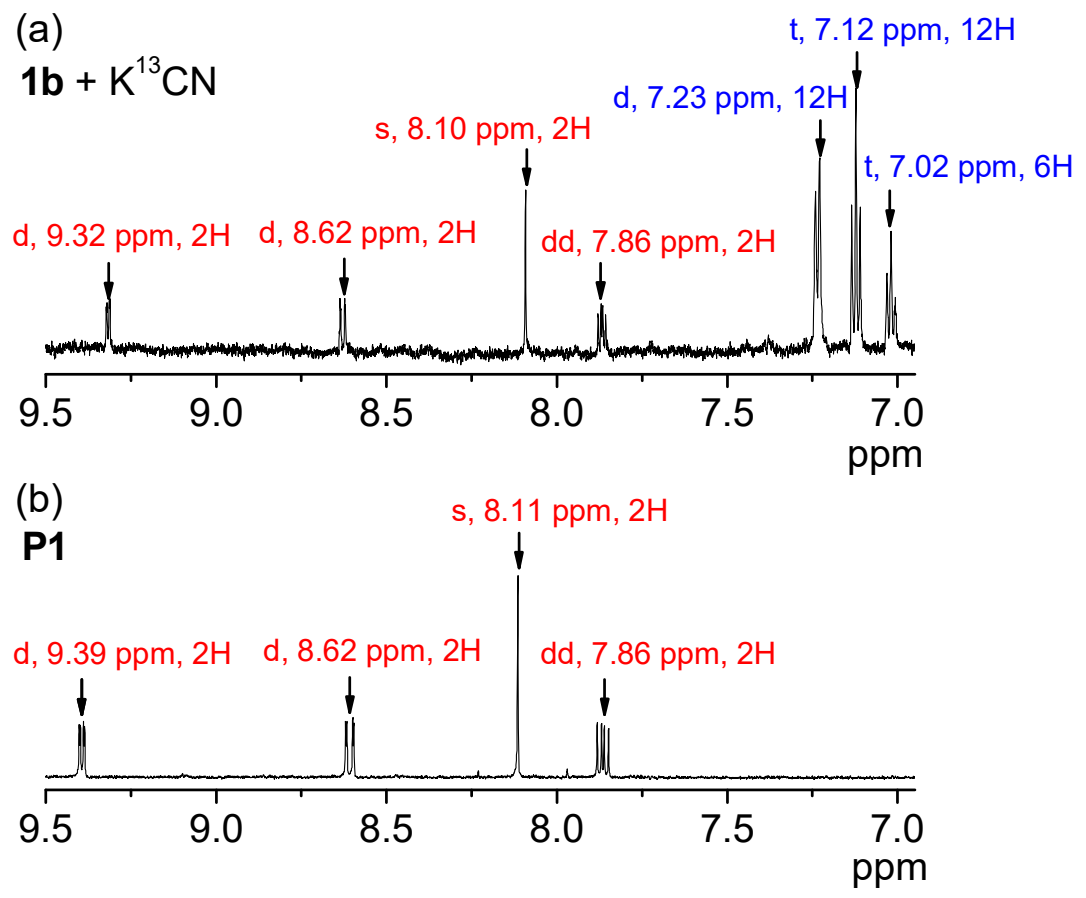

Figure S2. $\quad{ }^{1} \mathrm{H}$ NMR spectra $\left(600 \mathrm{MHz}, \mathrm{CD}_{3} \mathrm{CN}\right)$ of (a) $\mathbf{1 b}$ upon addition of 2.1 mole equivalents of $\mathrm{K}^{13} \mathrm{CN}$ and (b) $\mathbf{P 1}$.

(a)

$1 \mathrm{~b}+\mathrm{K}^{13} \mathrm{CN}$

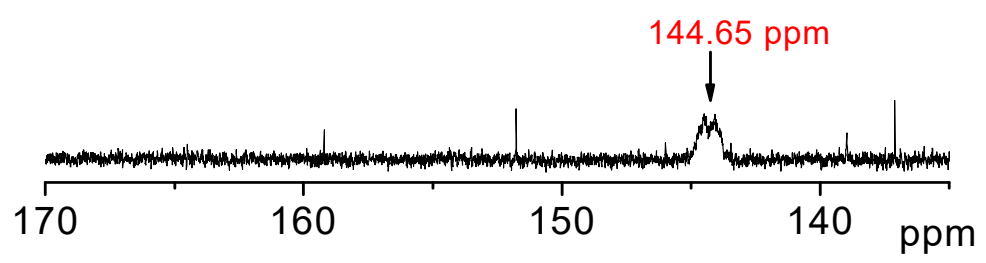

(b)

$\mathrm{K}^{13} \mathrm{CN}$

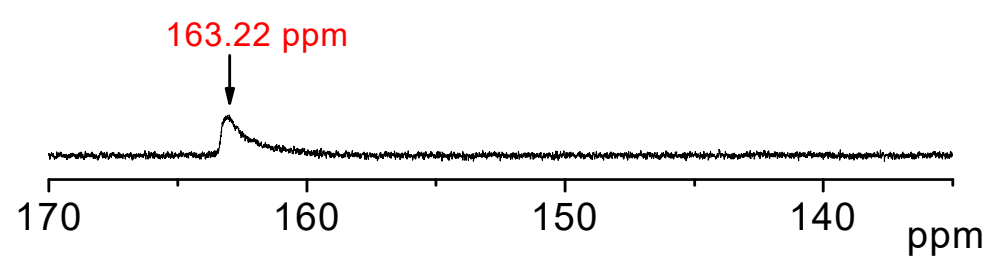

Figure S3. $\quad{ }^{13} \mathrm{C} N \mathrm{NMR}$ spectra $\left(151 \mathrm{MHz}, \mathrm{CD}_{3} \mathrm{CN}\right)$ of (a) $\mathbf{1 b}$ upon addition of 2.1 mole equivalents of $\mathrm{K}^{13} \mathrm{CN}$ and (b) $\mathrm{K}^{13} \mathrm{CN}$. 


\section{References}

(1) Demas, J. N.; Crosby, G. A. Measurement of Photoluminescence Quantum Yields Review. J. Phys. Chem. 1971, 75, 991-1024.

(2) Ishida, H.; Tobita, S.; Hasegawa, Y.; Katoh, R.; Nozaki, K. Recent Advances in Instrumentation for Absolute Emission Quantum Yield Measurements. Coord. Chem. Rev. 2010, 254, 2449-2458.

(3) Sheldrick, G. M. SHELX-97: Programs for Crystal Structure Analysis, Release 97-2; University of Göttingen: Göttingen, Germany, 1997. 